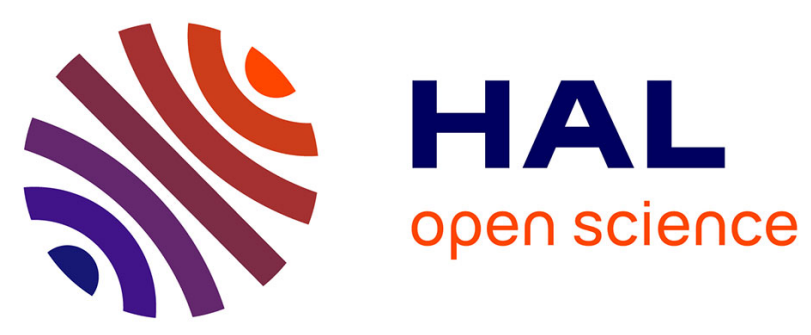

\title{
TWO-PHOTON ABSORPTION AND FLUORESCENCE WITH QUADRUPOLAR AND BRANCHED CHROMOPHORES. EFFECT OF STRUCTURE AND BRANCHING
}

Laurent Porrès, Olivier Mongin, Claudine Katan, Marina Charlot, Bharath Kumar Goud Bhatthula, Viatcheslav Jouikov, Thomas Pons, Jerome Mertz, Mireille Blanchard-Desce

\section{- To cite this version:}

Laurent Porrès, Olivier Mongin, Claudine Katan, Marina Charlot, Bharath Kumar Goud Bhatthula, et al.. TWO-PHOTON ABSORPTION AND FLUORESCENCE WITH QUADRUPOLAR AND BRANCHED CHROMOPHORES. EFFECT OF STRUCTURE AND BRANCHING. Journal of Nonlinear Optical Physics and Materials, 2004, 13 (03n04), pp.451-460. 10.1142/S0218863504002109. hal-01417623

HAL Id: hal-01417623

https://hal-univ-rennes1.archives-ouvertes.fr/hal-01417623

Submitted on 15 Dec 2016

HAL is a multi-disciplinary open access archive for the deposit and dissemination of scientific research documents, whether they are published or not. The documents may come from teaching and research institutions in France or abroad, or from public or private research centers.
L'archive ouverte pluridisciplinaire HAL, est destinée au dépôt et à la diffusion de documents scientifiques de niveau recherche, publiés ou non, émanant des établissements d'enseignement et de recherche français ou étrangers, des laboratoires publics ou privés. 


\title{
Two-Photon Absorption and Fluorescence with Quadrupolar and Branched Chromophores. Effect of Structure and Branching.
}

Laurent Porrès, ${ }^{\text {a }}$ Olivier Mongin, ${ }^{\text {a }}$ Claudine Katan, ${ }^{\text {a }}$ Marina Charlot, ${ }^{\text {a }}$ Bharath Kumar Goud Bhatthula, ${ }^{\mathrm{a}}$ Viatcheslav Jouikov, ${ }^{\mathrm{a}}$ Thomas Pons, ${ }^{\mathrm{b}}$ Jerome Mertz, ${ }^{\mathrm{b}, \#}$ and Mireille Blanchard$\operatorname{Desce}^{\mathrm{a}, *}$

${ }^{a}$ Synthèse et ElectroSynthèse Organiques (CNRS, UMR 6510), Université de Rennes 1, Institut de Chimie, Campus Scientifique de Beaulieu, Bât 10A, F-35042 Rennes Cedex, France

${ }^{b}$ Neurophysiologie et Nouvelles Microscopies (INSERM EPI 00-02, CNRS FRE 2500), Ecole Supérieure de Physique et Chimie Industrielles, 10 rue Vauquelin, F-75231 Paris Cedex 05, France

\begin{abstract}
The photophysical and two-photon absorption (TPA) properties of three homologous quadrupolar and one related three-branched chromophores were investigated. Design of the quadrupoles is based on the symmetrical functionalization of a biphenyl core. Modulation of the nonlinear absorptivity/transparency/photostability trade-off can be achieved by playing on the twist angle of the core and on the spacers (phenylene-vinylene vs phenylene-ethynylene). The quadrupolar chromophores combine high TPA cross-sections, high fluorescence quantum yield and solvent sensitive photoluminescence properties. The branched structure exhibits spectrally broadened TPA in the NIR region (up to $3660 \mathrm{GM}$ at $740 \mathrm{~nm}$ measured in the femtosecond regime) but reduced sensitivity to environment.
\end{abstract}

\section{Introduction}

Molecular two-photon absorption (TPA) has attracted increasing interest over recent years owing to the many applications it offers including 3D optical data storage, two-photon laser scanning microscopy (TLSM) imaging, photodynamic therapy, microfabrication and optical power limitation. ${ }^{1-6}$ This has initiated the design of compounds displaying enhanced TPA cross-sections along with specific features depending on the application. For instance, high solubility, ${ }^{7}$ high linear transmission at low intensities together with very large multiphoton absorptivities are desirable for optical power limitation. For TLSM applications, high fluorescence quantum yield $(\phi)$, suitable photostability and reduced phototoxicity are

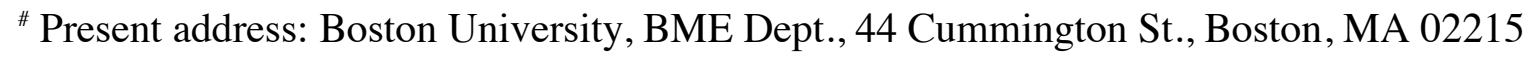


desirable in addition to TPA cross-sections $\left(\sigma_{2}\right)$ that are orders of magnitude larger than endogenous chromophores in the biological spectral window (700-1200 nm).

In recent years, following the pioneering routes opened by Prasad and coworkers, ${ }^{8,9}$ and Marder, Perry and Brédas, ${ }^{10}$ increasing effort has been devoted to the design and study of chromophores with large TPA cross-section exploring dipolar, ${ }^{9,11-14}$ quadrupolar, ${ }^{8,10,12,14-20}$ and even multidimensional and branched structures. ${ }^{21-30} \mathrm{~A}$ number of factors influence the TPA magnitude, such as electronic delocalization and intramolecular charge transfer phenomena, symmetry and dimensionality. A correlation between the square of the number of $\pi$-electrons in the conjugated systems and the maximum TPA that can be reached has been reported recently. ${ }^{31}$

In this context, we have investigated a series of homologous elongated chromophores of varying electronic structures (Fig. 1). In addition to investigating structure-property relationships, our aim was to identify appropriate structural combinations to optimize the TPA/transparency/solubility and TPA/fluorescence/photostability trade-offs. The series includes quadrupolar molecules 1-3 built from the symmetrical functionalization of a biphenyl core that is either free (1-2) or planarized when using dinonylfluorene (3). Solubilizing electron-donating end-groups are connected to the core via rigid phenylene-ethynylene (1) or semi-rigid phenylene-vinylene (2-3) conjugated spacers (Fig. 1). Finally, a branched structure (molecule 4) with three chromophores of type 3 connected via a common donating nitrogen has been investigated. Their synthesis is summarized in Scheme 1. Chromophore 1 was obtained by means of double Sonogashira coupling of 4,4'-diethynylbiphenyl 5 with reagent 6. ${ }^{17}$ Chromophores 2-3 were prepared via a double Wittig condensation carried out in solidliquid phase transfer conditions by reacting two equivalents of phosphonium salt $7^{32}$ with bisaldehyde 8 or two equivalents of phosphonium salt $9^{32}$ with bisaldehyde $10,{ }^{30}$ followed by catalytic isomerization. Finally a triple Horner-Wadsworth-Emmons condensation of trisphosphonate $11^{30}$ with three equivalents of aldehyde $12^{30}$ afforded branched chromophore 4 . The purity of chromophores 1-4 was checked by NMR, HRMS and elemental analysis prior to photophysical studies.

These chromophores show excellent solubility in apolar or weakly polar solvents (typically higher than $500 \mathrm{~g} . \mathrm{L}^{-1}$ in chlorinated solvents). 


\section{Results and discussion}

\subsection{Molecular geometry}

B3LYP/6-31G* ab-initio calculations ${ }^{33,} 34$ indicate that the conjugated system of quadrupolar chromophore $\mathbf{3}$ derived from the fluorene core is quasi planar (Fig. 2). In contrast, quadrupolar chromophores $\mathbf{1}$ and $\mathbf{2}$ derived from the biphenyl core display two planar conjugated branches twisted by about $35^{\circ}$ in the middle of the biphenyl moiety. It should be emphasized that the corresponding planar conformations of chromophores $\mathbf{1}$ and $\mathbf{2}$ are only $3 k T$ from the tilted lowest energy conformations. Moreover $s$-cis and $s$-trans type geometries are within a few tenths of $\mathrm{kcal}^{\mathrm{mol}}{ }^{-1}$. The branched chromophore 4 adopts a propeller-shaped structure, the conjugated branches being planar and twisted by about $40^{\circ}$ with respect to the trigonal central nitrogen.

\subsection{One-photon absorption and photoluminescence properties}

The photophysical characteristics of chromophores 1-4 are summarized in Table 1. The chromophores show an intense absorption band in the near UV or visible region depending on their structure. We observe that the chromophore built from the biphenyl core 2 shows a blueshifted and less intense absorption band with respect to its analogue derived from the fluorene core (3), indicative of a reduced electronic conjugation resulting from the core twist angle. Similarly, a definite blue and hypsochromic shift is observed when replacing the phenylenevinylene spacer (chromophore 2) by a phenylene-ethynylene unit (chromophore 1). As a result chromophore 1 maintains very good transparency in the visible region, of interest for optical power limitation applications. In addition, chromophore $\mathbf{1}$ also shows improved photostability. ${ }^{35}$

Changing the biphenyl core to a fluorene one does not lead to a shift of the emission band. A reduction of the Stokes shift is observed in relation most probably with the increased rigidity conferred by the planar fluorene core. In contrast, replacing the triple bond by a double bond in the conjugated spacers leads to a definite bathochromic shift of the emission bands. It also leads to an increase of the fluorescence lifetime, but to a slight decrease of the fluorescence quantum yield.

Due to coupling between the branches, both the absorption and emission bands of the three-branched chromophore $\mathbf{4}$ are red-shifted with respect to those of the corresponding quadrupolar branch $\mathbf{3}$, resulting in reduced transparency in the visible region. In contrast, fluorescence lifetime and quantum yields are only slightly reduced. 


\subsection{Solvatochromism}

Chromophores 1-3 show a pronounced positive emission solvatochromism (i.e. bathochromic shift with increasing polarity). Solvent polarity allows tuning of the photoluminescence in a significant way, typically from blue in toluene (Table 1$)$ to green $\left(\lambda_{\text {em }}\right.$ = 537, 545 and $532 \mathrm{~nm}$ for chromophores 1, 2 and 3 respectively) in DMSO. In contrast a slight red shift is observed in absorption (Table 1). This could be related to a stabilization of a (multi)polar emitting excited-state by polar solvents. Indeed HOMO-LUMO calculations reveal pronounced electronic redistributions, leading to bond length alternation reversal and intramolecular charge density shifts (Fig. 2).

In contrast, the three-branched chromophore $\mathbf{4}$ shows no noticeable absorption solvatochromism, much weaker emission solvatochromism than the corresponding quadrupolar branched chromophore 3 (Table 1). The weaker solvatochromic behavior could be related to the larger size (and thus larger solvent cavity radius) of molecule $\mathbf{4}$ as compared to 3 and possibly hindered solvation.

\subsection{Two-photon absorption}

The TPA spectra of chromophores 1-4 are shown in Fig. 3. In the series of quadrupolar chromophores 1-3, which have the same number $N$ of $\pi$-electrons in the conjugated system (as well as the same $N_{\text {eff }}$, calculated according to ref. ${ }^{31}$ ), playing on the nature of the conjugated spacer and of the core allows significant increase of the TPA magnitude: not surprisingly replacement of the phenylene-ethynylene spacer by a phenylene-vinylene spacer and of the biphenyl core by the planar fluorene core leads to a definite increase of the TPA cross-section in the NIR range: by more than factor two for $\mathbf{1} \rightarrow \mathbf{2}$ and by $50 \%$ for $\mathbf{2} \rightarrow \mathbf{3}$. As a consequence, chromophore 3 shows one of the highest normalized TPA cross-section $\left(\sigma_{2} / N\right)^{26}$ measured in the femtosecond regime while maintaining a high fluorescence quantum yield (Table 1).

In recent years, few experimental studies have focused on the effect of branching of chromophores on TPA. These studies lead to different outcomes: cooperative enhancement ${ }^{24}$, 26, 29,36, additive behavior ${ }^{22,23}$ or even reduction of TPA. ${ }^{36}$ However, it should be stressed that these results were obtained, in most cases, at one single wavelength. In this perspective, TPA measurements conducted on chromophores $\mathbf{3}$ and $\mathbf{4}$ are instructive (Fig. 4). Firstly, chromophore 4 shows one of the highest normalized TPA cross-sections $\left(\sigma_{2} / N\right)$ measured in the femtosecond regime for branched structure. ${ }^{26}$ Secondly, the ratio between the TPA cross- 
sections of chromophore $\mathbf{4}$ and chromophore $\mathbf{3}$ shown in Fig. 4 clearly shows that it depends significantly on the wavelength. At lower wavelength, the contribution of the three quadrupolar branches to the TPA amplitude seems roughly additive. Indeed $\sigma_{2} / N_{\text {eff }}^{2}$ is similar for chromophore 3 and 4 at $740 \mathrm{~nm}$. In contrast, at higher wavelength the ratio significantly increases, chromophore 4 overcoming chromophore 3 (Fig. 4). This observation is correlated with a definite TPA spectral broadening in the NIR region, of interest for biological imaging applications. Along this line it is interesting to note that, contrary to chromophore $\mathbf{3}$, a relative TPA maximum is observed at twice the one-photon maximum wavelength for chromophore $\mathbf{4}$, indicative that the lowest one-photon electronic exited-state becomes two-photon allowed as a result of symmetry lowering in the three-branched structure.

\subsection{Redox properties}

In addition to their photoluminescence properties, these molecules have low oxidation potential (e.g. $\mathrm{E}^{\circ}=0.832,0.612$ and $0.520 \mathrm{~V} / \mathrm{SCE}$ for chromophores 1, 2 and 3, respectively), suggesting that they could be of interest as hole transporters for OLED systems. Replacement of the phenylene-ethynylene spacer by a phenylene-vinylene spacer $(\mathbf{1} \rightarrow \mathbf{2})$ and of the biphenyl core by the planar fluorene core $(2 \rightarrow \mathbf{3})$ allows decreasing the oxidation potential, along with improved electronic conjugation along the conjugated system.

\section{Conclusion}

The present study provides evidence that modulation of the nonlinear absorptivity/transparency/photostability trade-off can be achieved by playing on the core and spacer structure. In particular, although the replacement of the double bond by a triple bond in the conjugated spacers leads to a 50\% decrease in the TPA cross-section at $740 \mathrm{~nm}$, this is counterbalanced by an increase in both photostability and transparency in the visible region. These chromophores also display very high solubility in apolar or weakly polar solvents. Such behavior is particularly attractive in the context of optimizing multiphoton absorbers for broadband optical power limitation. Preliminary experiments provide evidence that quadrupoles 1-3 show promising optical limiting properties in the visible region in the nanosecond regime. ${ }^{37}$

The series of quadrupolar chromophores show interesting photoluminescence properties: high fluorescence quantum yield and solvent sensitive photoluminescence properties (that can be tuned from blue to green). Finally, combination of quadrupolar chromophores within a 
three-branched structure results in a red-shift of both one-photon absorption and fluorescence bands, indicative of electronic interaction between the branches. Interestingly, the branching strategy also offers an interesting route for enhanced TPA in the NIR region via spectral broadening while maintaining high fluorescence yield and similar lifetime. In addition, the branching was found to significantly decrease the sensitivity of photoluminescence to solvent polarity providing evidence that geometrical branching has a profound influence not only on the electronic properties but also with the interaction of the chromophore with surrounding molecules.

\section{Acknowledgements}

MBD acknowledges financial support from CNRS (ATIP and NOI grants) and Rennes Métropole. L.P. received a fellowship from MRNT and M.C. from DGA. Calculations were supported by the "Centre Informatique National de l'Enseignement Supérieur” (CINESFrance).

\section{References}

1. D. A. Parthenopoulos and P. M. Rentzepis, Science 245, 843 (1989).

2. W. Denk, J. H. Strickler and W. W. Webb, Science 248, 73 (1990).

3. J. D. Bhawalkar, N. D. Kumar, C. F. Zhao and P. N. Prasad, J. Clin. Laser Med. Surg. 15, 201 (1997).

4. $\quad$ S. Kawata, H.-B. Sun, T. Tanaka and K. Takada, Nature 412, 697 (2001).

5. W. Zhou, S. M. Kuebler, K. L. Braun, T. Yu, J. K. Cammack, C. K. Ober, J. W. Perry and S. R. Marder, Science 296, 1106 (2002).

6. G. S. He, G. C. Xu, P. N. Prasad, B. A. Reinhardt, J. C. Bhatt and A. G. Dillard, Opt. Lett. 20, 435 (1995).

7. In order to get to the highest effective concentration, neat compounds such as liquid or gels are highly desirable: G. S. He, R. Helgeson, T.-C. Lin, Q. Zheng, F. Wudl and P. N. Prasad, IEEE J. Quantum Electron. 39, 1003 (2003).

8. G. S. He, G. C. Xu, P. N. Prasad, B. A. Reinhardt, J. C. Bhatt, R. McKellar and A. G. Dillard, Opt. Lett. 20, 435 (1995).

9. G. S. He, L. Yuan, N. Cheng, J. D. Bhawalkar, P. N. Prasad, L. L. Brott, S. J. Clarson and B. A. Reinhardt, J. Opt. Soc. Am. B 14, 1079 (1997).

10. M. Albota, D. Beljonne, J.-L. Brédas, J. E. Ehrlich, J.-Y. Fu, A. A. Heikal, S. E. Hess, T. Kogej, M. D. Levin, S. R. Marder, D. McCord-Maughon, J. W. Perry, H. Röckel, M. Rumi, G. Subramaniam, W. W. Webb, X.-L. Wu and C. Xu, Science 281, 1653 (1998).

11. K. D. Belfield, D. J. Hagan, E. W. Van Stryland, K. J. Schafer and R. A. Negres, Org. Lett. 1, 1575 (1999).

12. O.-K. Kim, K.-S. Lee, H. Y. Woo, K.-S. Kim, G. S. He, S. H. Guang, J. Swiatkiewicz and P. N. Prasad, Chem. Mater. 12, 284 (2000).

13. L. Antonov, K. Kamada, K. Ohta and F. S. Kamounah, Phys. Chem. Chem. Phys. 5, 1193 (2003). 


\section{J. Nonlinear Optic. Phys. Mat. 13, 451 (2004). \\ DOI: http://dx.doi.org/10.1142/S0218863504002109}

14. B. Strehmel, A. M. Sarker and H. Detert, ChemPhysChem 4, 249 (2003).

15. L. Ventelon, M. Blanchard-Desce, L. Moreaux and J. Mertz, Chem. Commun., 2055 (1999).

16. L. Ventelon, S. Charier, L. Moreaux, J. Mertz and M. Blanchard-Desce, Angew. Chem., Int. Ed. 40, 2098 (2001).

17. O. Mongin, L. Porrès, L. Moreaux, J. Mertz and M. Blanchard-Desce, Org. Lett. 4, 719 (2002).

18. S. J. K. Pond, M. Rumi, M. D. Levin, T. C. Parker, D. Beljonne, M. W. Day, J.-L. Brédas, S. R. Marder and J. W. Perry, J. Phys. Chem. A 106, 11470 (2002).

19. A. Abbotto, L. Beverina, R. Bozio, A. Facchetti, C. Ferrante, G. A. Pagani, D. Pedron and R. Signorini, Org. Lett. 4, 1495 (2002).

20. O. K. Kim, K. S. Lee, Z. Huang, W. B. Heuer and C. S. Paik-Sung, Opt. Mater. 21, 559 (2003).

21. M. P. Joshi, J. Swiakiewicz, F. Xu, P. N. Prasad, B. A. Reinhardt and R. Kannan, Opt. Lett. 23, 1742 (1998).

22. A. Adronov, J. M. J. Fréchet, G. S. He, K.-S. Kim, S.-J. Chung, J. Swiatkiewicz and P. N. Prasad, Chem. Mater. 12, 2838 (2000).

23. S.-J. Chung, T.-C. Lin, K.-S. Kim, G. S. He, J. Swiatkiewicz, P. N. Prasad, G. A. Baker and F. V. Bright, Chem. Mater. 13, 4071 (2001).

24. M. Drobizhev, A. Karotki, A. Rebane and C. W. Spangler, Opt. Lett. 26, 1081 (2001).

25. B. R. Cho, K. H. Son, H. L. Sang, Y.-S. Song, Y.-K. Lee, S.-J. Jeon, J. H. Choi, H. Lee and M. Cho, J. Am. Chem. Soc. 123, 10039 (2001).

26. A. Abbotto, L. Beverina, R. Bozio, A. Facchetti, C. Ferrante, G. A. Pagani, D. Pedron and R. Signorini, Chem. Commun., 2144 (2003).

27. O. Mongin, J. Brunel, L. Porrès and M. Blanchard-Desce, Tetrahedron Lett. 44, 2813 (2003).

28. J. Yoo, S. K. Yang, M.-Y. Jeong, H. C. Ahn, S.-J. Jeon and B. R. Cho, Org. Lett. 5, 645 (2003).

29. M. Drobizhev, A. Karotki, Y. Dzenis, A. Rebane, Z. Suo and C. W. Spangler, J. Phys. Chem. B 107, 7540 (2003).

30. O. Mongin, L. Porrès, C. Katan, T. Pons, J. Mertz and M. Blanchard-Desce, Tetrahedron Lett. 44, 8121 (2003).

31. M. G. Kuzyk, J. Chem. Phys. 119, 8327 (2003).

32. L. Porrès, B. K. G. Bhatthula and M. Blanchard-Desce, Synthesis, 1541 (2003).

33. For the sake of simplicity, calculations have been conducted on chromophores where the alkyl solubilizing chains have been replaced by methyl substituents.

34. Gaussian 98, Revision A.11; Frisch, M. J.; Trucks, G. W.; Schlegel, H. B.; Scuseria, G. E.; Robb, M. A.; Cheeseman, J. R.; Zakrzewski, V. G.; Montgomery Jr., J. A.; Stratmann, R. E.; Burant, J. C.; Dapprich, S.; Millam, J. M.; Daniels, A. D.; Kudin, K. N.; Strain, M. C.; Farkas, O.; Tomasi, J.; Barone, V.; Cossi, M.; Cammi, R.; Mennucci, B.; Pomelli, C.; Adamo, C.; Clifford, S.; Ochterski, J.; Petersson, G. A.; Ayala, P. Y.; Cui, Q.; Morokuma, K.; Malick, D. K.; Rabuck, A. D.; Raghavachari, K.; Foresman, J. B.; Cioslowski, J.; Ortiz, J. V.; Stefanov, B. B.; Liu, G.; Liashenko, A.; Piskorz, P.; Komaromi, I.; Gomperts, R.; Martin, R. L.; Fox, D. J.; Keith, T.; AlLaham, M. A.; Peng, C. Y.; Nanayakkara, A.; Gonzalez, C.; Challacombe, M.; Gill, P. M. W.; Johnson, B.; Chen, W.; Wong, M. W.; Andres, J. L.; Head-Gordon, M.; S., R. E.; Pople, J. A.; Gaussian, Inc., Pittsburgh PA, 2001.

35. owing in particular to the absence of cis-trans isomerization.

36. S.-J. Chung, K.-S. Kim, T.-C. Lin, G. S. He, J. Swiatkiewicz and P. N. Prasad, J. Phys. Chem. B 103, 10741 (1999). 
37. D. Riehl, N. Izard, O. Mongin, M. Blanchard-Desce, to be published.

38. MOLEKEL 4.0; Flükiger, P.; Lüthi, H. P.; Portmann, S.; Weber, J.; Swiss Center for Scientific Computing, Manno (Switzerland), 2000.

39. C. Xu and W. W. Webb, J. Opt. Soc. Am. B 13, 481 (1996).

\section{Captions}

Fig. 1. Series of structurally-related quadrupolar (1-3) and branched (4) chromophores. $N$ is the total number of $\pi$-electrons, $N_{\text {eff }}$ is the effective number of $\pi$-electrons, calculated according to ref. ${ }^{31}$ and $l$ the length of the conjugated system.

Fig. 2. B3LYP/6-31G*34 optimized geometry and frontier orbitals ${ }^{38}$ of chromophore $3^{33}$ HOMO-1 (a), HOMO (b), LUMO (c), and LUMO+1 (d).

Fig. 3. Two-photon excitation spectra of chromophores 1-4 in toluene.

Fig. 4. Effect of branching on TPA.

Scheme 1. Synthetic route to chromophores 1-4, based on multiple Wittig, HornerWadsworth-Emmons and Sonogashira couplings. 


\section{Table 1}

One and two-photon photophysical data of chromophores 1-4 in toluene.

\begin{tabular}{|c|c|c|c|c|c|c|c|c|c|c|c|}
\hline Compound & $\begin{array}{c}\lambda_{\max }^{\text {abs }} \\
(\mathrm{nm})\end{array}$ & $\begin{array}{c}\varepsilon_{\max } \\
\left(\mathrm{cm}^{-1} \cdot \mathrm{mol}^{-1} . \mathrm{L}\right)\end{array}$ & $\begin{array}{c}\Delta v_{\mathrm{abs}}{ }^{a} \\
\left(10^{3} \mathrm{~cm}^{-1}\right)\end{array}$ & $\begin{array}{l}\lambda_{\max }^{\mathrm{em}} \\
(\mathrm{nm})\end{array}$ & $\begin{array}{c}\text { Stokes Shift } \\
\left(10^{3} \mathrm{~cm}^{-1}\right)\end{array}$ & $\begin{array}{c}\Delta v_{\mathrm{em}}{ }^{b} \\
\left(10^{3} \mathrm{~cm}^{-1}\right)\end{array}$ & $\Phi^{c}$ & $\begin{array}{c}\tau^{d} \\
(\mathrm{~ns})\end{array}$ & $\begin{array}{c}\sigma_{2}^{e} \\
(\mathrm{GM})\end{array}$ & $\begin{array}{l}\sigma_{2} / N^{f} \\
(\mathrm{GM})\end{array}$ & $\begin{array}{c}\sigma_{2} / N_{\text {eff }}^{2 g} \\
(\mathrm{GM})\end{array}$ \\
\hline 1 & 374 & 83000 & 0.14 & 424 & 3.15 & 1.61 & 0.90 & 0.70 & 350 & 12.5 & 0.45 \\
\hline 2 & 401 & 83800 & 0.19 & 456 & 3.06 & 1.27 & 0.84 & 0.82 & 905 & 32.5 & 1.15 \\
\hline 3 & 415 & 96200 & - & 457 & 2.21 & 1.64 & 0.79 & 0.87 & 1470 & 52.5 & 1.87 \\
\hline 4 & 428 & 244000 & - & 471 & 2.13 & 0.48 & 0.74 & 0.85 & 3660 & 43.5 & 1.56 \\
\hline
\end{tabular}

${ }^{a}$ absorption solvatochromic shift $=1 / \lambda_{\mathrm{abs}}($ toluene $)-1 / \lambda_{\mathrm{abs}}\left(\mathrm{CHCl}_{3}\right)$.

${ }^{b}$ emission solvatochromic shift $=1 / \lambda_{\mathrm{em}}($ toluene $)-1 / \lambda_{\mathrm{em}}\left(\mathrm{CHCl}_{3}\right)$.

${ }^{c}$ Fluorescence quantum yield determined relative to fluorescein in $0.1 \mathrm{~N} \mathrm{NaOH}$.

${ }^{d}$ Experimental fluorescence lifetime determined using time-correlated single-photon counting (TCSPC).

${ }^{e}$ TPA cross-section measured at $740 \mathrm{~nm}$ in toluene; $1 \mathrm{GM}=10^{-50} \mathrm{~cm}^{4}$.s.photon ${ }^{-1}$. TPEF measurements were performed using a mode-locked Ti:sapphire laser delivering 80 fs pulses at $80 \mathrm{MHz}$, calibrating with fluorescein. ${ }^{39}$

$f$ TPA cross-section at $740 \mathrm{~nm}$ normalized by the number $N$ of $\pi$-electrons in the conjugated system.

${ }^{g}$ TPA cross-section at $740 \mathrm{~nm}$ normalized by the effective number $N_{\text {eff }}$ of $\pi$-electrons in the conjugated system. ${ }^{31}$ 


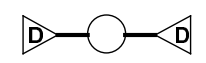

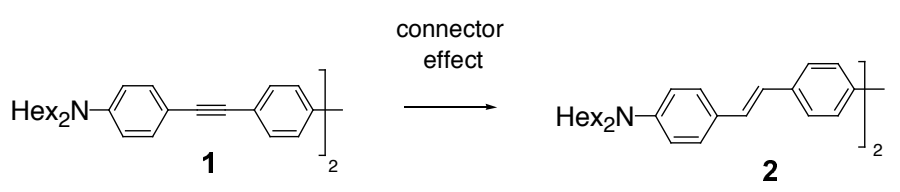

$I=2.4 \mathrm{~nm} \quad N=N_{\text {eff }}=28$

$I=2.3 \mathrm{~nm} \quad N=N_{\text {eff }}=28$

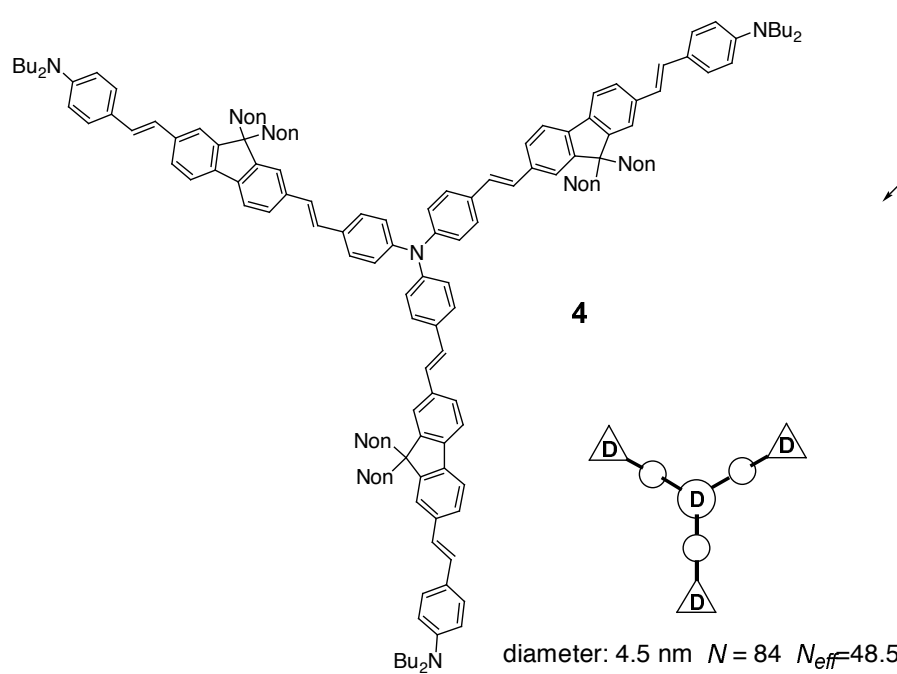

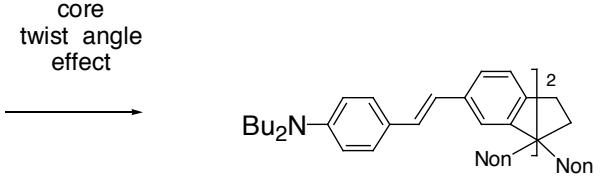

3

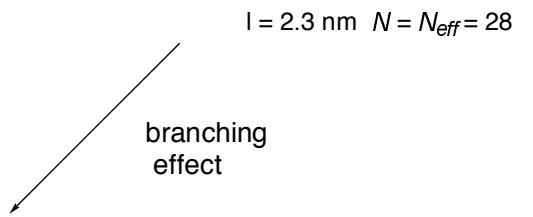

Fig. 1
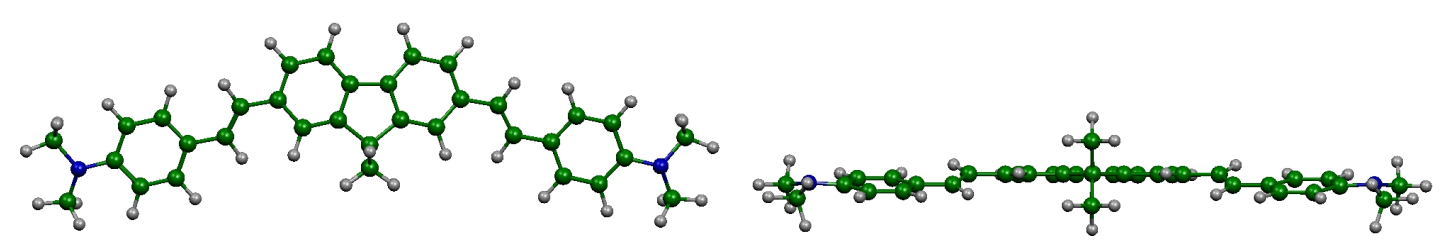

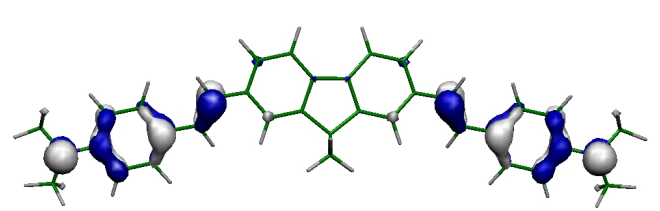

a

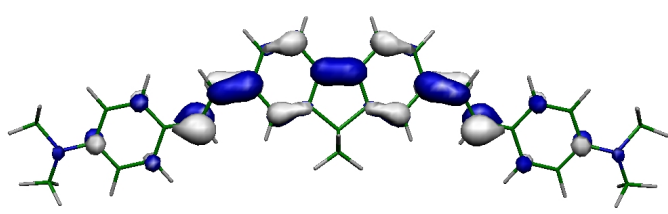

c

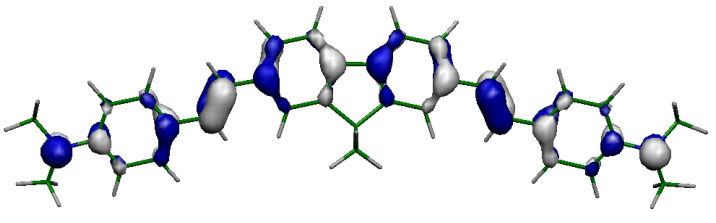

b

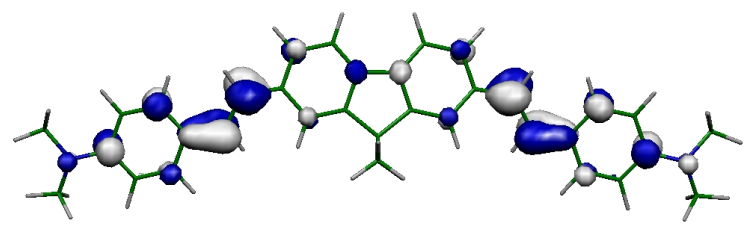

d

Fig. 2 


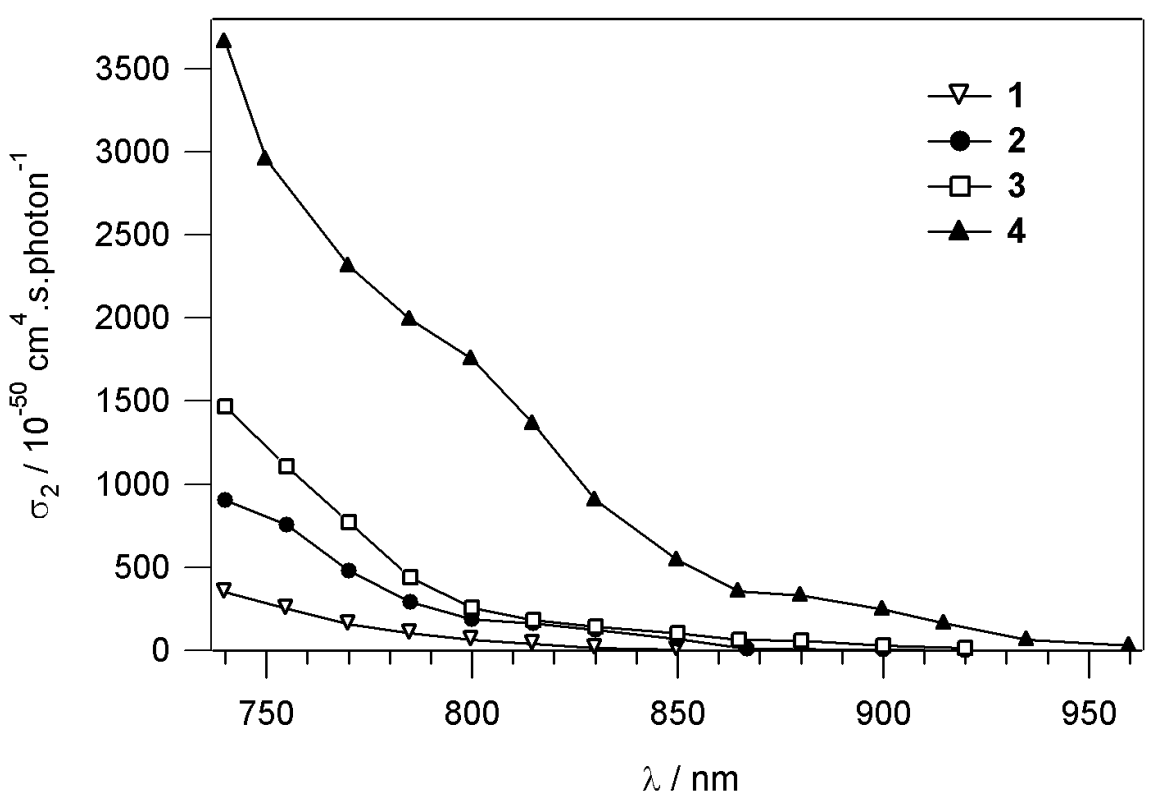

Fig. 3

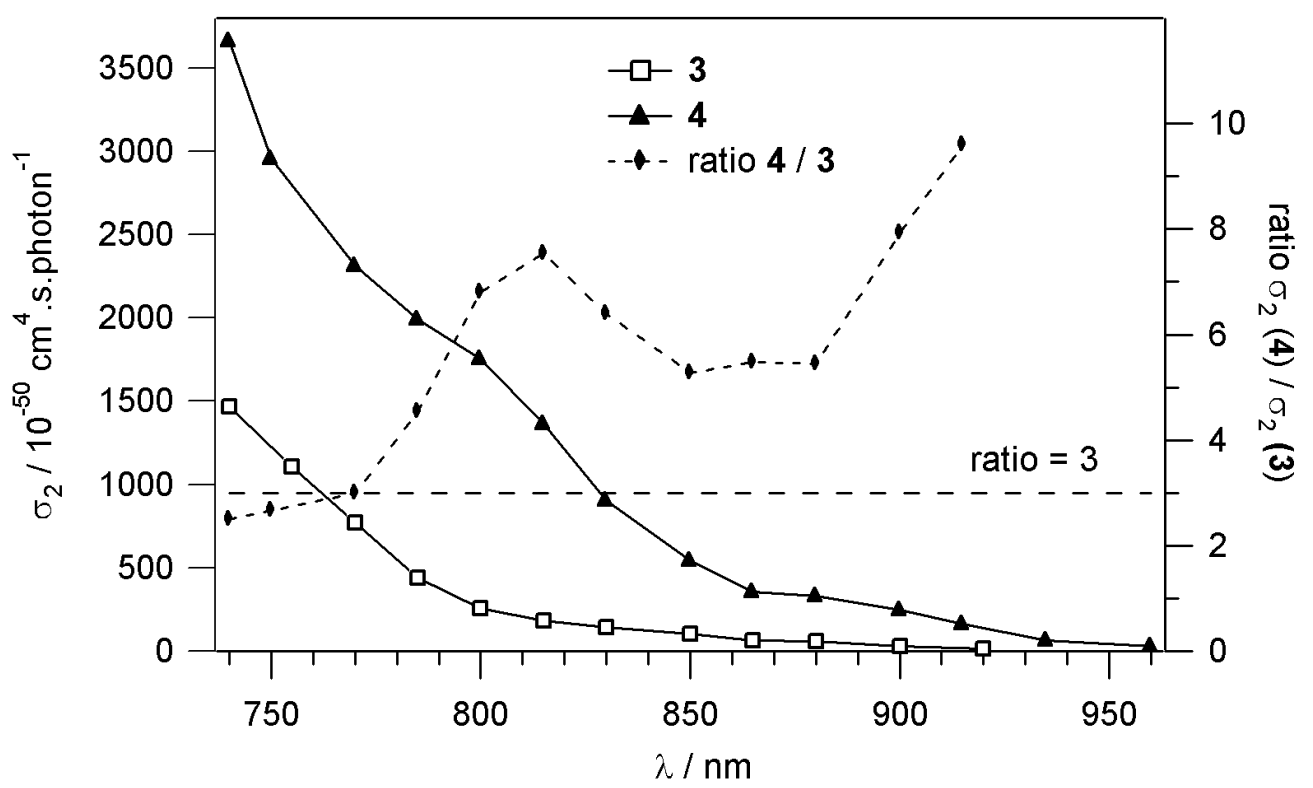

Fig. 4 

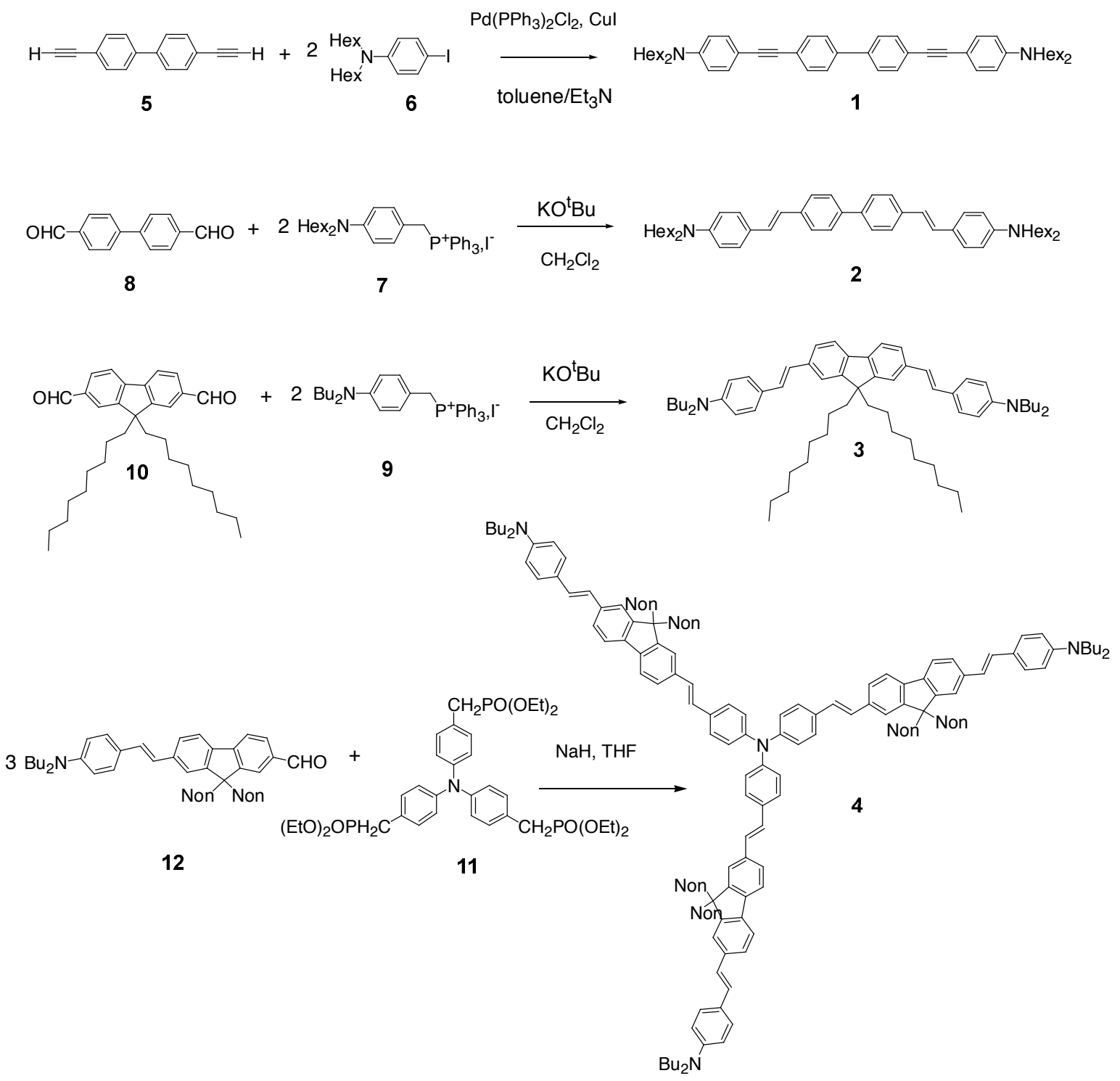

Scheme 1 